\title{
Novel Patterns of Ultraviolet Mutagenesis and Weigle Reactivation in Staphylococcus aureus and Phage $\phi 11$
}

\author{
By J. K. THOMPSON AND M. G. R. HART* \\ Sub-Department of Genetics, The Queen's University of Belfast, David Keir Building, \\ Stranmillis Road, Belfast BT7 1NN
}

(Received 23 June 1980)

\begin{abstract}
The effects of u.v. irradiation on the survival of Staphylococcus aureus and its phage $\phi 11$ were studied. The recA and $u v r$ mutations affected their survival in a similar way to synonymous mutations in Escherichia coli. Weigle reactivation (W-reactivation) of $\phi 11$ occurred in wild-type $S$. aureus and in a $u v r$ mutant but to a lesser extent than has been found for phage $\lambda$ in $E$. coli. Reactivation was $\operatorname{rec} A$-dependent and was accompanied by u.v.-induced mutagenesis in a temperature-sensitive mutant of $\phi 11$. Bacterial mutation to streptomycin resistance was induced by u.v. and was also rec $A$-dependent. In $S$. aureus, as in $E$. coli, u.v. was a more effective mutagen in the $u v r$ genetic background. However, a dose-squared response for u.v.-induced mutation of wild-type and $u v r$ strains of $S$. aureus to streptomycin resistance, and of a trp auxotroph to tryptophan independence, was found only with u.v. doses below $1 \mathrm{~J} \mathrm{~m}^{-2}$. We suggest that, in relation to the Uvr mechanism of DNA repair, u.v. mutagenesis in $S$. aureus involves both repairable and non-repairable lesions. As in $E$. coli, the $u v r$ genetic background reduced the u.v. dose required for maximal W-reactivation of u.v.-irradiated phage. However, there was no enhancement of Wreactivation by post-irradiation broth incubation of $S$. aureus. Our results are compatible with a non-inducible mechanism for this phenomenon.
\end{abstract}

\section{IN TRODUCTION}

Numerous effects of u.v. irradiation in Escherichia coli are thought to be due to the induction of 'SOS functions' (Witkin, 1974; Radman, 1974). They include mutagenic Weigle reactivation (W-reactivation) of phage $\lambda$ (Weigle, 1953; Defais et al., 1971), $\lambda$ prophage induction (Brooks \& Clark, 1967), bacterial mutagenesis (Witkin, 1974), enhanced synthesis of protein X (Gudas \& Pardee, 1975) and several others controlled by the recA and lexA gene products of $E$. coli (for review, see Witkin, 1976). Among these effects, the mechanism of $\lambda$ prophage induction is best understood. It involves the eventual proteolytic cleavage of the lambda repressor by the recA gene product protein X (Roberts et al., 1978). The signal for protein $\mathrm{X}$ induction is not known but the similar kinetics of induction of $\lambda$ prophage and the other functions suggest that they have mechanisms in common (Defais et al., 1976).

Much less is known about SOS functions in other bacteria, although the absence of u.v.-inducible error-prone repair can be inferred from an inability to sustain u.v.-induced mutations. By this criterion, error-prone repair is absent in Micrococcus radiodurans (Sweet \& Moseley, 1974, 1976), in Haemophilus influenzae Rd (Kimball et al., 1977) and in Proteus mirabilis (Hutchinson \& Medill, 1954; Böhme, 1963). Pollard \& Snipes (1977) found no evidence of u.v.-inducible radioresistance or inhibition of post-irradiation DNA degradation in Pseudomonas BAL-31, of marine origin. However, Hofemeister \& Böhme (1975) demonstrated a low level of $\mathrm{W}$-reactivation of a temperate phage correlated with relatively weak recA lexA dependent DNA repair in P. mirabilis. Hofemeister (1977) established that post-irradiation DNA degradation in this organism was an inducible rec function. In Bacillus 
subtilis a full range of SOS functions has been found; these resemble those of $E$. coli, although some differences in the kinetics of W-reactivation were noted (Yasbin, 1977a, b). U.v. mutability has been shown in myxobacteria (Grimm, 1978) but there was no DNA repair in the Mycoplasma species studied by Ghosh et al. (1977). Clearly different patterns of u.v.-associated functions exist.

U.v. induction of prophage in Staphylococcus aureus is well known (Wyman et al., 1974; Smith \& Dunican, 1974; Smith et al., 1975). In addition to several mutants defective in host cell reactivation (Goering \& Pattee, 1971), rec strains with properties similar to those of $E$. coli recA (Inoue et al., 1972; Wyman et al., 1974) and E. coli recB,C (Goering \& Pattee, 1971) have been isolated.

We have studied repair functions in a wild-type $S$. aureus strain and its u.v.-sensitive mutants. Our results on the survival of u.v.-irradiated $S$. aureus and host cell reactivation of u.v.-damaged bacteriophage $\phi 11$ suggest resemblances with the Uvr and Rec mechanisms in $E$. coli and phage $\lambda$. U.v. mutagenesis occurs for two mutations investigated and mutations to streptomycin resistance depend on the recAl gene product. This is correlated with recAl-dependent $\mathrm{W}$-reactivation and mutagenesis in a temperature-sensitive mutant of the temperate phage $\phi 11$. Although error-prone repair functions are found in $S$. aureus, they do not conform to the model of inducible SOS repair developed for E. coli.

\section{METHODS}

Bacteria and bacteriophages. These are listed in Table 1. The effects of the uvr and recA mutations on the u.v. survival of host bacteria and phage, and on W-reactivation, were compared with those of their wild-type alleles in strain RN1349. In all other experiments comparisons were made with the original wild-type strain RN450.

Media. Bacteria were cultured in nutrient broth consisting of $1.5 \%(\mathrm{w} / \mathrm{v})$ tryptose, $0.25 \%(\mathrm{w} / \mathrm{v})$ soy peptone, $0.5 \%(\mathrm{w} / \mathrm{v})$ yeast extract and $0.5 \%(\mathrm{w} / \mathrm{v}) \mathrm{NaCl}$. The medium was solidified with $1.2 \%(\mathrm{w} / \mathrm{v})$ agar when required. Ingredients were obtained from London Analytical \& Bacteriological Media, Pendleton, Salford, Lancs. Soft nutrient agar was $2.0 \%(\mathrm{w} / \mathrm{v})$ blood agar base no. 2 (Oxoid). For phage propagation $4 \mathrm{mM}-\mathrm{CaCl}_{2}$ was added after autoclaving. Streptomycin media contained $500 \mu \mathrm{g}$ streptomycin sulphate $\mathrm{ml}^{-1}$ (Glaxo). The tryptophan auxotroph was grown on the modified casein hydrolysate minimal medium (CHM) of Lindberg et al. (1972) with the addition of $20 \mu \mathrm{g}$ L-tryptophan $\mathrm{ml}^{-1}$. Novick buffer was as described by Novick \& Brodsky (1972). Phosphate buffer ( $\mathrm{pH} \mathrm{7.0)} \mathrm{contained,} \mathrm{per} \mathrm{litre,} 3.0 \mathrm{~g} \mathrm{KH}_{2} \mathrm{PO}_{4}, 7.0 \mathrm{~g} \mathrm{Na}_{2} \mathrm{HPO}_{4}, 4.0 \mathrm{~g} \mathrm{NaCl}$ and $0.2 \mathrm{~g} \mathrm{MgSO}_{4} .7 \mathrm{H}_{2} \mathrm{O}$.

$N$-Methyl- $N^{\prime}$-nitro- $N$-nitrosoguanidine $(M N N G)$ mutagenesis. For bacterial mutagenesis the method of Adelberg et al. (1965) was used. Mutants of phage $\phi 11$ were obtained by the method of Cohen et al. (1977).

Ultraviolet irradiation. A Hanovia Chromatolite portable ultraviolet lamp delivering $0.55 \mathrm{~J} \mathrm{~m}^{-2} \mathrm{~s}^{-1}$ at a distance of $9.5 \mathrm{~cm}$ or $0.034 \mathrm{~J} \mathrm{~m}^{-2} \mathrm{~s}^{-1}$ at $38 \mathrm{~cm}$ was used. Output was measured with a Blak-Ray short wave meter

Table 1. Staphylococcus aureus bacterial and phage strains

Strain

Bacteria

RN450 (8325-4)

RN1349 (8325-4 his-7)

RN972 (8325-4 his-7 uvr-420)

RN981 (8325-4 his-7 uvr-461)

RN450 trp-1

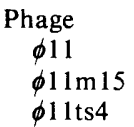

Characteristics and derivation

Wild-type; strain NCTC 8325 cured of three prophages

Histidine-requiring mutant of RN450

Ultraviolet-sensitive derivative of RN 1349

Ultraviolet-sensitive derivative of RN1349; also

deficient in generalized recombination (Wyman et al., 1974)

MNNG-induced tryptophan-requiring mutant of RN450

Wild-type; isolated as a prophage from NCTC 8325

Clear-plaque mutant of $\phi 11$

MNNG-induced temperature-sensitive mutant of $\phi 11$
Source

R. Novick*

R. Novick

R. Novick

R. Novick

This laboratory

R. Novick

R. Novick

This laboratory

* Public Health Research Institute of the City of New York, New York, U.S.A. 
(J 225; Ultra-Violet Products, San Gabriel, Calif., U.S.A.). Operations were performed in sodium light to avoid photoreactivation.

Ultraviolet survival curves. Overnight broth cultures were diluted 10 -fold in prewarmed nutrient broth and incubated with aeration to a cell density of $2 \times 10^{8}$ to $5 \times 10^{8}$ colony-forming units (c.f.u.) $\mathrm{ml}^{-1}$. The bacteria were resuspended in chilled phosphate buffer and subjected to mild sonication (for $60 \mathrm{~s}$ at amplitude 1 using a Dawe Soniprobe type 7532A; Dawe Instruments, London W3 0SD) to disperse clusters. This treatment yielded $80 \%$ of colony-forming units as single cells and gave the maximum plate count; it had no effect on the u.v. sensitivity of the bacteria. Sonicated bacterial suspensions were diluted 100 -fold in phosphate buffer and $5 \mathrm{ml}$ amounts were irradiated in $9 \mathrm{~cm}$ diam. glass Petri dishes with constant agitation. Survivors were counted in soft nutrient agar overlays after $48 \mathrm{~h}$ incubation at $37^{\circ} \mathrm{C}$. Phage suspensions at a concentration of about $10^{8}$ plaque-forming units (p.f.u.) $\mathrm{ml}^{-1}$ were irradiated in Novick buffer and survivors were counted in soft nutrient agar overlays containing indicator bacteria after overnight incubation at $30^{\circ} \mathrm{C}$.

Ultraviolet reactivation experiments. Exponential-phase cultures were resuspended in 0.1 vol. Novick buffer and sonicated. Samples (about $10^{9}$ c.f.u. $\mathrm{ml}^{-1}$ ) were irradiated and $0.2 \mathrm{ml}$ sub-samples were adsorbed $(15 \mathrm{~min}$ at $37^{\circ} \mathrm{C}$ ) to an equal volume of phage previously irradiated to a survival of about $10^{-3}$. The multiplicity of infection was never greater than $10^{-2}$ and preliminary experiments showed that 70 to $90 \%$ of the phage were adsorbed during this period. After adsorption, molten soft nutrient agar containing the indicator bacterium was added to the tubes and the contents were rapidly mixed and poured over the agar base. Plaques were counted after incubation at $30^{\circ} \mathrm{C}$.

Phage mutagenesis associated with $W$-reactivation. Reversion frequencies of the temperature-sensitive mutant phage $\phi 11$ ts 4 were used as a measure of u.v.-induced phage mutagenesis. Phage irradiated to a survival of $10^{-2}$ were adsorbed at $37^{\circ} \mathrm{C}$ to irradiated or unirradiated host cells and plated as described above. The plates were held at $30^{\circ} \mathrm{C}$ for precisely $10 \mathrm{~min}$ to allow solidification of the agar overlay and then incubated at $41.5^{\circ} \mathrm{C}$. Revertant plaques were counted after $24 \mathrm{~h}$.

Post-irradiation broth incubation. Exponential-phase bacteria were irradiated with a u.v. dose of $12 \mathrm{~J} \mathrm{~m}^{-2}$, resuspended in fresh nutrient broth at a density of $10^{9} \mathrm{c}$.f.u. $\mathrm{ml}^{-1}$ and incubated at $37^{\circ} \mathrm{C}$ with aeration. At intervals samples were withdrawn, adsorbed to irradiated phage $\phi 11 \mathrm{~m} 15$ or $\phi 11 \mathrm{ts} 4$ and plated as described above.

Mutation frequency response (MFR) for u.v.-induced streptomycin resistance. Exponential-phase bacteria were resuspended in phosphate buffer at a density of $10^{8}$ to $10^{9}$ c.f.u. $\mathrm{ml}^{-1}$ and sonicated. Samples were irradiated, plated in thin soft nutrient agar overlays and incubated at $37^{\circ} \mathrm{C}$ to allow phenotypic expression. A preliminary experiment had shown no significant increase in the number of mutants after $2.5 \mathrm{~h}$ for strain RN450 (wt) and $3.5 \mathrm{~h}$ for strain RN972 (uvr) and these periods were used for phenotypic expression. A thin layer of soft nutrient agar containing streptomycin sulphate was then added to each plate to give a final concentration of $500 \mu \mathrm{g} \mathrm{ml}$ and incubation was continued for a further $48 \mathrm{~h}$ at $37^{\circ} \mathrm{C}$ before streptomycin-resistant colonies were counted.

Reversion of tryptophan auxotrophs. Bacteria were grown in nutrient broth to mid-exponential phase $\left(2 \times 10^{8}\right.$ to $5 \times 10^{8}$ c.f.u. $\mathrm{ml}^{-1}$ ), washed twice in 3 vol. buffer and sonicated. Irradiated samples were plated directly on unsupplemented $\mathrm{CHM}$ to enumerate prototrophs. Unsupplemented medium allowed residual growth and expression of u.v.-induced mutations; supplemented medium was not used because it increased the background levels of spontaneous mutants and reduced the accuracy of the determinations. Survivors were estimated by plating on CHM with tryptophan, and also on nutrient agar.

\section{RESULTS}

Ultraviolet survival and host cell reactivation in $S$. aureus wild-type, recA 1 and uvr mutants

The survival curves for strain RN1349 and its two u.v.-sensitive derivatives RN972 and RN981 are shown in Fig. 1. Strain RN981 was originally selected as a u.v.-sensitive mutant also defective in generalized recombination and has been well characterized as an $E$. coli recA analogue (Wyman et al., 1974). Strain RN972 was selected from a series of 12 other u.v.-sensitive derivatives of RN1349 because of its extreme u.v. sensitivity and uniformity of colonial morphology.

Strain RN981 (recA1) gave a survival curve similar in shape to those of $E$. coli recA mutants (Howard-Flanders \& Boyce, 1966; Howard-Flanders \& Theriot, 1966): the bacteria were extremely sensitive to low doses $\left(<0.5 \mathrm{~J} \mathrm{~m}^{-2}\right)$ with a dose for $37 \%$ survival $\left(\mathrm{D}_{37}\right)$ of $0.08 \mathrm{~J} \mathrm{~m}^{-2}$ but the fraction surviving at higher doses was more resistant. Strains RN450 (wt), RN1349 (wt) and RN972 (uvr) have shouldered survival curves (see Figs 1 and 5). $D_{37}$ values, calculated from the initial portion of the curves, were $21.0 \mathrm{~J} \mathrm{~m}^{-2}$ for the wild-type and $0.15 \mathrm{~J} \mathrm{~m}^{-2}$ for the uvr mutant (RN972). 


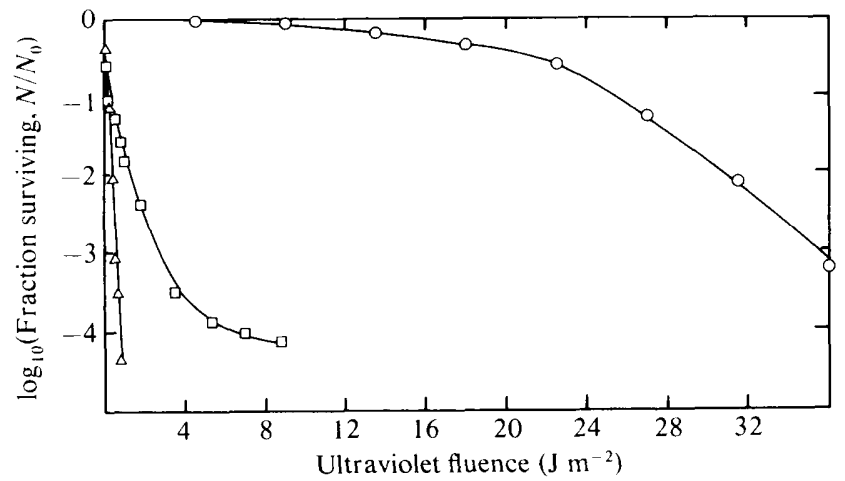

Fig. 1. Survival of u.v.-irradiated $S$. aureus. Exponential-phase cells of strains RN1349 [wt] (O), RN972 $\mid$ uvr $\mid(\triangle)$ and RN981 $|\operatorname{rec} A|(\square)$ were resuspended in buffer (about $10^{6}$ c.f.u. ml ${ }^{-1}$ ), sonicated and u.v.-irradiated. Survivors were enumerated in soft nutrient agar overlays after incubation at $37^{\circ} \mathrm{C}$ for $48 \mathrm{~h}$.

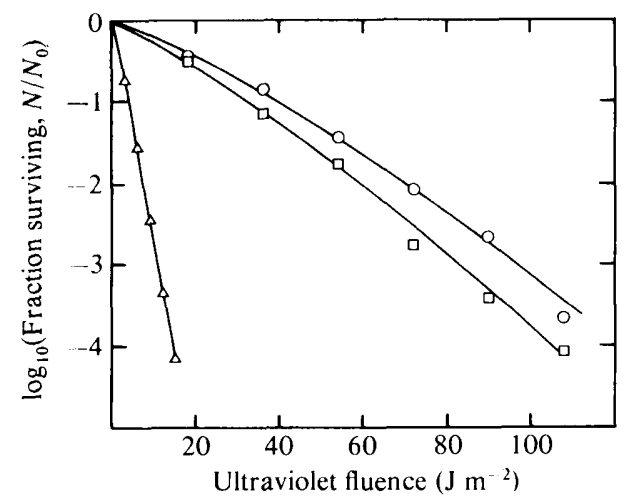

Fig. 2. Survival of u.v.-irradiated phage $\phi 11$ plated on different $S$. aureus host strains. Phage suspensions (about $10^{8}$ p.f.u. $\mathrm{ml}^{-1}$ ) were u.v.-irradiated and plated with strains RN1349 [wt] (O), RN972 |uvr| $(\triangle)$ or RN981 $|\operatorname{rec} A|(\square)$ in soft nutrient agar overlays. Survivors were counted after incubation at $30^{\circ} \mathrm{C}$ for $24 \mathrm{~h}$.

Figure 2 shows the survival of phage $\phi 11$ plated on three different strains. Strain RN972 shows the her phenotype $\left(\mathrm{D}_{37} 2.0 \mathrm{~J} \mathrm{~m}^{-2}\right)$ typical of excision-repair-deficient mutants of $E$. coli reactivating phage $\lambda$ (Harm, 1963). As previously reported by Wyman et al. (1974) using phage $\phi 11 \mathrm{~m} 15$, strain RN981 was able to reactivate phage $\phi 11$ to almost the same extent as the wild-type. The $D_{37}$ values were $20.5 \mathrm{~J} \mathrm{~m}^{-2}$ and $15.5 \mathrm{~J} \mathrm{~m}^{-2}$, respectively, when phage $\phi 11$ was plated on RN1349 (wt) and RN981 (recAl).

\section{Ultraviolet reactivation experiments}

Weigle reactivation and mutagenesis. Figure $3(a)$ shows the results of $\mathrm{W}$-reactivation experiments with u.v.-irradiated phage $\phi 11$. The wild-type strain (RN1349) was able to reactivate the damaged phage giving a fourfold increase in the number of phages recovered when the host bacteria were irradiated at a dose of $12 \mathrm{~J} \mathrm{~m}^{-2}$. Strain RN972 (uvr) showed reactivation of phage $\phi 11$ only when the phage was heavily irradiated (to $5 \times 10^{-5}$ survival). However, W-reactivation could be obtained in strain RN972 by using the clear-plaque mutant $\phi 11 \mathrm{~m} 15$ (Fig. $3 b$ ). In neither of the strains was reactivation as extensive as in the corresponding $E$. coli strains reactivating phage $\lambda$ (Hart \& Ellison, 1970; Radman \& Devoret, 1971). No increased reactivation was detectable in irradiated strain RN981 (recAl) with either phage (Figs $3 a, b$ ). 


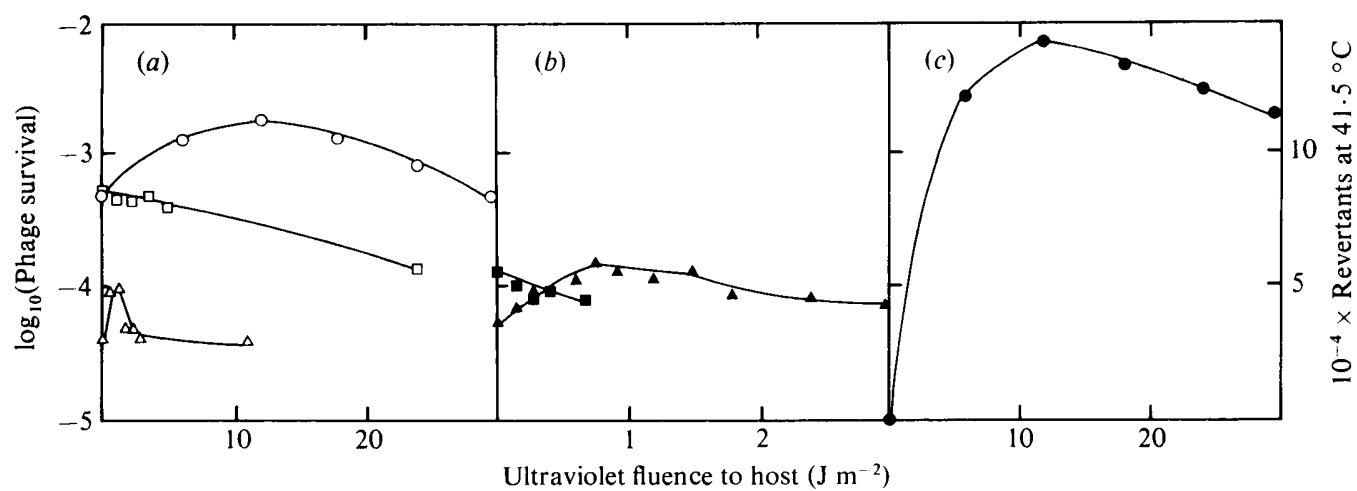

Fig. 3. Weigle reactivation and mutagenesis of phage $\phi 11$ by different $S$. aureus hosts. (a) Phage $\phi 11$ was u.v.-irradiated and adsorbed to irradiated strains RN1349 [wt] (O), RN972 [uvr] ( $\triangle$ ) or RN981 $[r e c A](\square)$. After adsorption the mixture was plated in soft nutrient agar overlays using an $h \mathrm{cr}$ strain (RN972) as indicator bacterium. Plaques were counted after $24 \mathrm{~h}$ at $30^{\circ} \mathrm{C}$. (b) U.v.-irradiated phage $\phi 11 \mathrm{~m} 15$ (a clear-plaque mutant of $\phi 11$ ) was adsorbed to irradiated strain RN972 [uvr] (A) or RN981 $[\mathrm{rec} A](\mathbb{D})$ and plated as described above. (c) Temperature-sensitive phage $\phi 11 \mathrm{ts} 4$, u.v.-irradiated to a survival of $10^{-2}$, was adsorbed to irradiated strain RN450 [wt] (O) for $15 \mathrm{~min}$ at $37^{\circ} \mathrm{C}$. After plating, incubation was continued at the restrictive temperature $\left(41.5^{\circ} \mathrm{C}\right)$. Revertant plaques were counted after $24 \mathrm{~h}$.

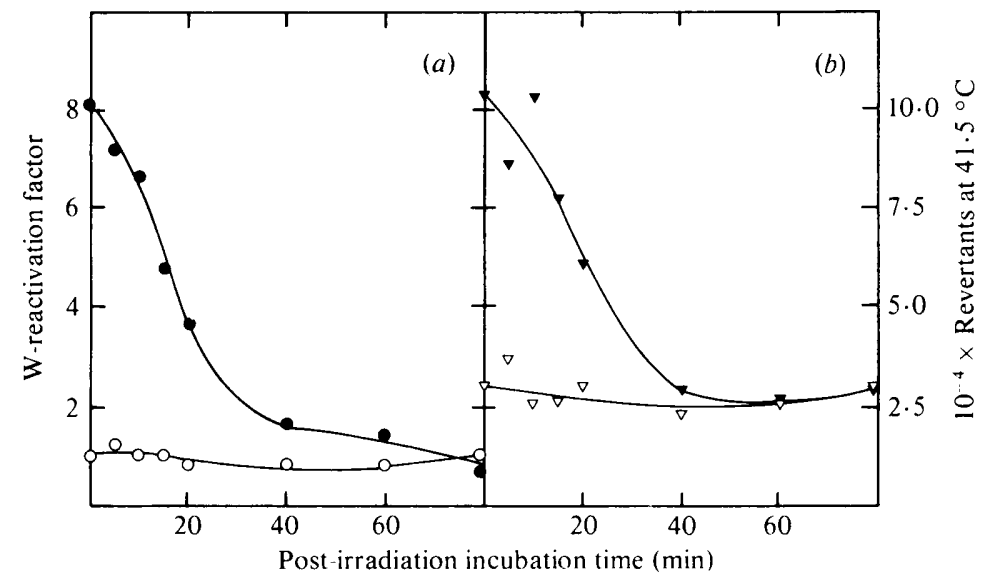

Fig. 4. Effect of post-irradiation nutrient broth incubation of wild-type $S$. aureus strain RN450 on (a) W-reactivation of phage $\phi 11 \mathrm{ml} 15$ and $(b)$ mutagenesis of the temperature-sensitive mutant $\phi 11$ ts 4 . Exponential-phase cells of strain RN450 were resuspended in Novick buffer and irradiated to give maximum W-reactivation $\left(12 \mathrm{~J} \mathrm{~m}^{-2}\right)$. A sample was plated immediately with u.v.-irradiated $\phi 11 \mathrm{~m} 15$ (survival $10^{-3}, \bigcirc$ ) or u.v.-irradiated $\phi 11 \mathrm{ts} 4$ (survival $10^{-2}, \nabla$ ) as described in Methods. The remaining cells were resuspended in fresh nutrient broth at $37^{\circ} \mathrm{C}$ and incubated with shaking. At intervals. samples were withdrawn and plated with the u.v.-irradiated phage. Controls using unirradiated $\phi 11 \mathrm{~m} 15$ (O) and unirradiated $\phi 11$ ts $4(\nabla)$ were also included. Plaques were counted after incubation at $30^{\circ} \mathrm{C}$ for $\phi 11 \mathrm{~m} 15$ or $41.5^{\circ} \mathrm{C}$ for $\phi 11$ ts 4 .

The data in Fig. $3(c)$ show the increase in frequency of revertants of the temperaturesensitive phage mutant $\phi 11$ ts 4 during similar $\mathrm{W}$-reactivation experiments in the wild-type host bacterium. The reversion frequency was maximal at a dose of $12 \mathrm{~J} \mathrm{~m}^{-2}$, the same as for W-reactivation. Plaques of phage $\phi 11$ on the mutant host bacteria are indistinct at the restrictive temperature and it was therefore not possible to determine whether u.v. mutagenesis occurred in the rec and $u v r$ genetic backgrounds.

Effect of post-irradiation incubation on Weigle reactivation and mutagenesis. Figure 4 shows the extent of $\mathrm{W}$-reactivation of phage $\phi 11 \mathrm{~m} 15$ and number of u.v.-induced revertants 

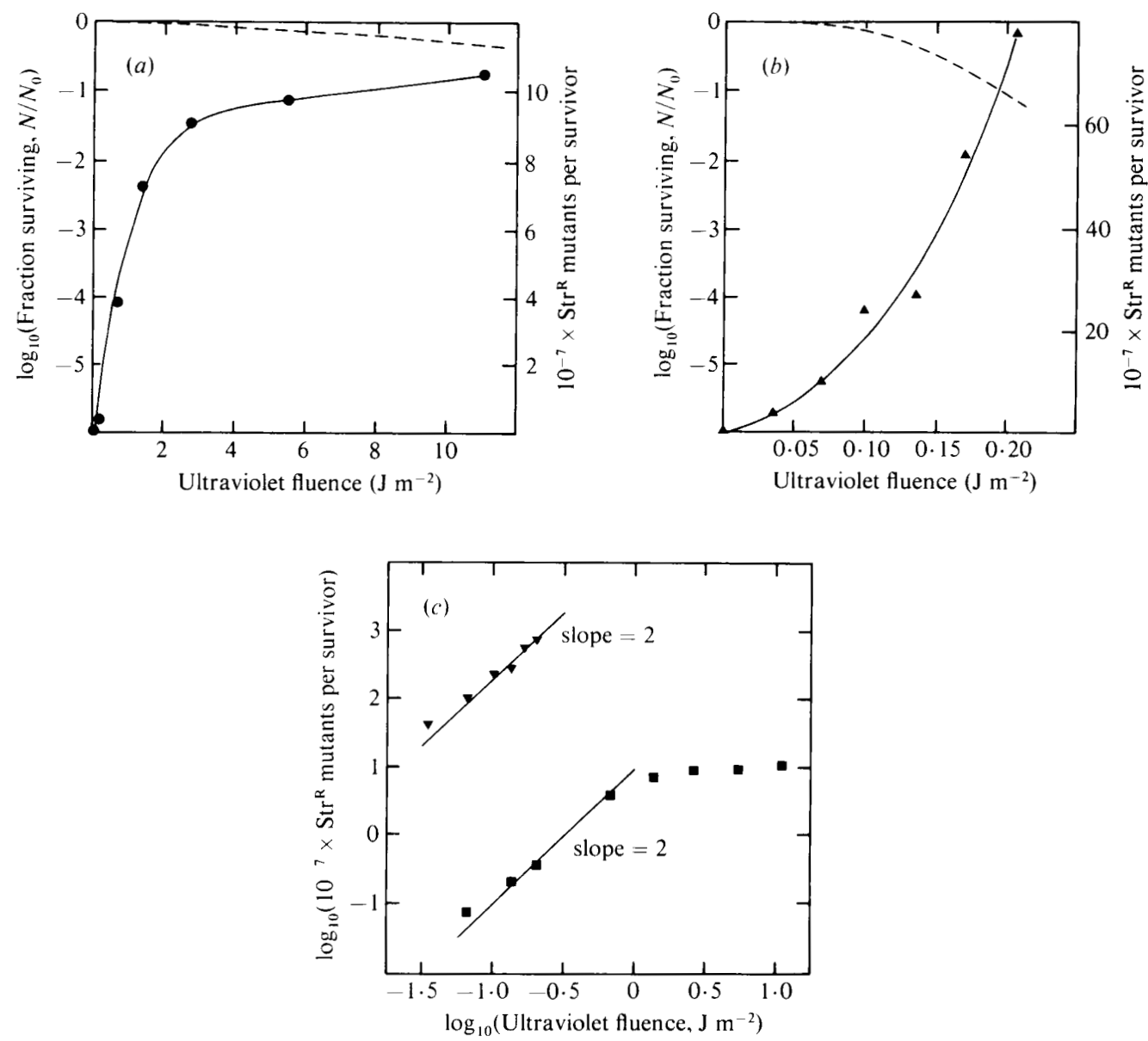

Fig. 5. Mutation frequency response for streptomycin resistance in u.v.-irradiated $S$. aureus RN450 and RN972. Exponential-phase cells of strains RN450 [wt] $(a)$ and RN972 [uvr] $(b)$ were irradiated and about $10^{8}$ c.f.u. were plated in soft nutrient agar overlays. After incubation at $37{ }^{\circ} \mathrm{C}$ to allow phenotypic expression, an additional thin layer of soft nutrient agar containing streptomycin sulphate (final concn $500 \mu \mathrm{g} \mathrm{ml}^{-1}$ ) was added to each plate. Streptomycin-resistant $\left(\mathrm{Str}^{\mathrm{R}}\right)$ colonies were counted after a further $48 \mathrm{~h}$ incubation at $37^{\circ} \mathrm{C}$. Points represented on the graph are corrected for the spontaneous mutation frequency $\left(<4 \times 10^{-7}\right)$ and are the means for three separate experiments. Dashed lines represent the surviving fraction determined in soft nutrient agar overlays. (c) Log-log plot of the same data: strain RN450 [wt] $(\mathbf{0})$, strain RN972 [uvr] $(\boldsymbol{\nabla})$. Theoretical (slope $=2)$ lines are shown.

of $\phi 11$ ts 4 obtained when bacteria irradiated at a dose of $12 \mathrm{~J} \mathrm{~m}^{-2}$ were incubated at $37^{\circ} \mathrm{C}$ in broth for various periods before infection with the irradiated phage. No improvement in reactivation or increase in mutation occurred and there was a steady decline in both during the incubation. These results differ from those obtained for $E$. coli, in which W-reactivation and mutagenesis were both enhanced by post-irradiation incubation (Defais et al., 1976).

\section{Ultraviolet mutagenesis of S. aureus}

Forward mutation to streptomycin resistance. The mutation frequency responses (MFR) of strains RN450 (wt) and RN972 (uvr) to u.v. irradiation in relation to their survival are shown in Fig. 5. An absolute increase in number of streptomycin-resistant mutants occurred in both strains. Considerably more mutants were induced per unit dose for the $u v r$ strain than the wild-type strain and the maximum yield was greater. A similar result has been described for 

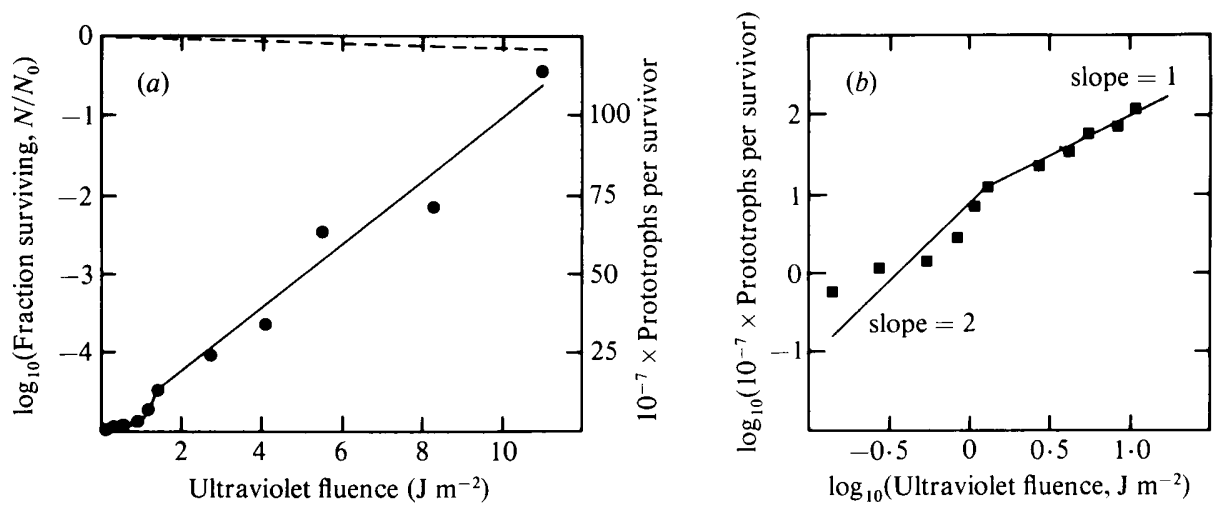

Fig. 6. (a) Mutation frequency response for u.v.-induced reversion to prototrophy of $S$. aureus strain RN450 trp-1. Washed exponential-phase cells of RN450 trp-l were u.v.-irradiated and samples were spread on CHM agar at a density of $3 \times 10^{7}$ to $4 \times 10^{8} \mathrm{ml}^{-1}$. Prototrophs were counted after incubation for $48 \mathrm{~h}$ at $37^{\circ} \mathrm{C}$. Survivors were determined on CHM agar containing $20 \mu \mathrm{g} \mathrm{L}$-tryptophan $\mathrm{ml}^{-1}$. Points are the means for at least three separate experiments and are corrected for the spontaneous mutation frequency $\left(6 \cdot 1 \times 10^{-7}\right)$. The dashed line represents the surviving fraction. $(b)$ Log-log plot of the same data. Theoretical (slope $=1$ and slope $=2$ ) lines are shown.

u.v.-induced streptomycin resistance in analogous mutants of $E$. coli (Witkin, 1966). A $\log -\log$ plot of the data (Fig. $5 c$ ) shows that there was a dose-squared relationship between u.v. dose and frequency of streptomycin-resistant mutants in the low $\left(<1 \mathrm{~J} \mathrm{~m}^{-2}\right)$ dose range for both strains. No streptomycin-resistant derivatives of strain RN981 (recAl) were obtained using the methods described and plating out $10^{9}$ c.f.u., confirming its u.v. stability and similarity with recA mutants of $E$. coli.

Ultraviolet-induced reversion of RN450 trp-1 to prototrophy. The MFR of the tryptophan auxotroph to increasing u.v. dose is shown in Fig. $6(a)$. The survival of the irradiated bacteria was poorer when plated on nutrient agar than on CHM with added tryptophan; the frequency of revertants was calculated using the latter figures. The results were similar to those obtained with mutation to streptomycin resistance. Mutations to prototrophy were induced at u.v. fluences which had little effect on bacterial viability. The MFR curve shows an apparent linear relationship between u.v. fluence and induction of prototrophs. A log-log plot of the data is shown in Fig. $6(b)$. As with the experiments on mutation to streptomycin resistance in strain RN450, the dose-squared relationship is probably confined to the low dose range $(<1 \mathrm{~J}$ $\mathrm{m}^{-2}$ ). However, data obtained in the low dose range are less reliable owing to the increased significance of spontaneous background mutations.

\section{DISCUSSION}

The u.v. survival and host cell reactivating characteristics of the $S$. aureus mutants RN972 and RN981 confirm their resemblance, respectively, to the excisionless (uvr) and recombination-deficient (recA) mutants of E. coli (Wyman et al., 1974). Table 2 shows the approximate number of dimers estimated to constitute a single lethal hit for u.v. irradiation of $S$. aureus, phage $\phi 11$ and $E$. coli. The u.v. dose for maximal W-reactivation in wild-type $S$. aureus $\left(12 \mathrm{~J} \mathrm{~m}^{-2}\right)$ was lower than in wild-type $E$. coli $\left(30 \mathrm{~J} \mathrm{~m}^{-2}\right)$ (Defais et al., 1971). However, the bacterial survival level for maximal W-reactivation in $S$. aureus $(>80 \%)$ was similar to that in E. coli (Witkin, 1976), and also B. subtilis (Yasbin, 1977a), but differed from that in $P$. mirabilis, in which maximal reactivation occurs in wild-type bacteria at a survival level of only $0.1 \%$ (Hofemeister, 1977). In the $S$. aureus uvr mutant the maximal reactivating dose was $1 \mathrm{~J} \mathrm{~m}^{-2}$; at this dose the level of bacterial survival was much lower (about $0.1 \%$ ), as in E. coli uvr mutants (Witkin, 1976). For both wild-type and uvr strains, 
Table 2. Estimated pyrimidine dimers per genome per lethal hit for u.v. irradiation of $S$. aureus, phage $\phi 11$ and E. coli, obtained from u.v. survival curves

The $S$. aureus data were estimated from the $\mathrm{D}_{37}$ values of the survival curves in Figs 1 and 2 , assuming 60 dimers per genome for each $\mathrm{J} \mathrm{m}^{-2}$ (Witkin, 1976), and correcting for the higher $\mathrm{A}+\mathrm{T}$ content of S. aureus (65-68\%; Garrity et al., 1969) and phage $\phi 11(62.5-64.8 \%$; Brown et al.. 1972). It is assumed that the $S$. aureus genome is of similar size and has a similar distribution of thymines to that of E. coli. The mol. wt of phage $\phi 11$ DNA is $3.27 \times 10^{7}$ (Brown et al.. 1972). Dimer formation in phage DNA is from Radman et al. (1970). The E. coli data are from Howard-Flanders \& Boyce (1966): the figures in brackets are recalculated on the basis of 60 dimers per genome for each $\mathrm{J} \mathrm{m}^{-2}$.

\begin{tabular}{lccc} 
& \multicolumn{3}{c}{ Bacterial genotype } \\
\cline { 2 - 4 } wild-type & uvr & recA \\
S. aureus & 2230 & 16 & 8 \\
Phage $\phi 11$ on S. aureus & $13 \cdot 3$ & $1 \cdot 3$ & $10 \cdot 0$ \\
E. coli & 3700 & 60 & 22 \\
& $(2960)$ & $(48)$ & $(18)$
\end{tabular}

maximum W-reactivation was more pronounced for the clear-plaque mutant phage $\phi 11 \mathrm{~m} 15$ than for the wild-type phage $\phi 11$.

Prophage reactivation - the repair of a damaged superinfecting phage by recombination with a related prophage - could be a complication in $\mathrm{W}$-reactivation experiments. Strain RN450 was cured of three prophages by u.v. induction (Novick, 1967), but Rudin \& Lindberg (1975) have indicated that defective prophages may still be present. The survival of u.v.-damaged phage $\phi 11$ was almost identical on strain RN450 and its recA derivative, strain RN981. Since a functional recA gene is necessary for prophage reactivation in $E$. coli (Hart $\&$ Ellison, 1970) it is unlikely that prophage reactivation was a factor in our experiments.

There is a similarity between the u.v.-associated SOS functions of $S$. aureus and those of $E$. coli. All occur to some extent independently of the $u v r$ gene products but are dependent on recA function. U.v. induction of prophage $\phi 11$ from lysogens of strain RN450 has been shown by Wyman et al. (1974) and by Smith \& Dunican (1974), and from strain RN972 (uvr) (unpublished results). Strain RN981 ( $\mathrm{rec} A$ ) lysogens rarely release phage spontaneously and are not u.v.-inducible for phage $\phi 11$ (Wyman et al., 1974). Some W-reactivation occurs in both the wild-type and the $u v r$ strain and it is accompanied by mutagenesis of the temperature-sensitive mutant phage $\phi 11$ ts 4 in strain RN450. W-reactivation did not occur in the recAl mutant.

Bacterial mutagenesis to streptomycin resistance takes place in both the wild-type and $u v r$ mutant but not in the recAl mutant, thus indicating that $r e c A$-dependent error-prone repair of u.v. damage is present in $S$. aureus. We have also obtained u.v.-induced reversion in the tryptophan auxotroph derived from strain RN450.

In E. coli, a uniform hypothesis has been devised for the induction of SOS functions including W-reactivation and error-prone DNA repair (Witkin, 1974; Radman, 1974). However, some data do not support fully the concept of uniform coordinate induction. In lon strains of $E$. coli, for example, the u.v. dose required to inhibit cell division and produce filaments is much lower than for other SOS functions, but the effect is subject to excision repair (Bridges et al., 1977). Thus, although unexcised pyrimidine dimers signal the division inhibition, fewer are needed than for other SOS functions. There are also aspects of the responses we observed in $S$. aureus which do not conform to the SOS hypothesis.

In $E$. coli, low u.v. doses result in small increases in the mutation frequency but higher doses are relatively more effective (Bridges et al., 1967). This has been interpreted (Doudney, 1976) as being a consequence of the inducibility of error-prone repair, for which low doses must provide both the premutational damage and the inducing signal. In $S$. aureus u.v.-irradiated in the 1 to $12 \mathrm{~J} \mathrm{~m}^{-2}$ range, which is associated with SOS induction in wild-type $E$. coli, tryptophan prototrophs accumulated linearly with u.v. dose. Very few new 
streptomycin-resistant mutants arose in this range. Thus, in $S$. aureus no evidence has been obtained for a dose-squared relationship in the 1 to $12 \mathrm{~J} \mathrm{~m}^{-2}$ range. In the low dose range $(0$ to $1 \mathrm{~J} \mathrm{~m}^{-2}$ ) both wild-type strains accumulated mutants exponentially with dose-squared kinetics. The $u v r$ strain RN972 also accumulated streptomycin-resistant mutants with dose-squared kinetics in the same low dose range, but it yielded more mutants per unit dose indicating that, as in E. coli, the premutational lesions are unexcised dimers. Staphylococcus aureus differs from $E$. coli in the important respect that dose-squared kinetics occur only in the low dose range, irrespective of the capability of the bacterium to carry out the excision repair. U.v. mutagenesis, although dependent on unexcised dimers for premutational lesions, must also require a photoproduct which is apparently not subject to excision or acts at the pre-excision stage.

W-reactivation in $S$. aureus follows the $E$. coli pattern, with the $u v r$ genetic background reducing the u.v. dose required for maximal reactivation. It is therefore related to the presence of unexcised dimers.

Thus our results suggest that in $S$. aureus there is a difference between the basic mechanisms of bacterial mutagenesis and $\mathrm{W}$-reactivation of phage. Bacterial mutagenesis depends partly on a u.v. photoproduct which is not subject to the Uvr repair mechanism. $\mathrm{W}$-reactivation involves lesions which are repairable by this mechanism.

W-reactivation and its associated mutagenesis in $S$. aureus are at a maximum immediately after irradiation and decline during broth incubation. In $E$. coli, W-reactivation and mutagenesis reach a maximum only after $50 \mathrm{~min}$ broth incubation; this is related to a requirement for protein synthesis (Defais et al., 1976). The absence of a broth incubation effect in $S$. aureus suggests that new protein synthesis is not required. However, the requirement may be less, or the rate of synthesis may be greater, so that necessary synthesis is completed before the end of the phage adsorption period.

The $S$. aureus results are compatible with a hypothesis of DNA repair in which recA protein is present constitutively at a concentration sufficient for these functions. A related mechanism has been discussed by Bridges (1978), in which deoxyribonucleoside $5^{\prime}$ monophosphates built up by DNA polymerase idling (Villani et al., 1978) act directly to suppress the 'proof-reading' function of the polymerase. The recA protein is allocated a direct role in the stabilization of the replicating DNA (Kerr \& Hart, 1972; Hofemeister, 1977; Bridges, 1978; Satta et al. 1979) and need not be involved in repressor cleavage or new protein synthesis.

\section{J. K. T. acknowledges a Grant Aids to Study award from the Department of Agriculture for Northern Ireland.}

\section{REFERENCES}

Adelberg, E. A., Mandel, M. \& Chen, G. C. C. (1965). Optimal conditions for mutagenesis by $N$-methyl- $N^{\prime}$-nitro- $N$-nitrosoguanidine in Escherichia coli K12. Biochemical and Biophysical Research Communications 18, 788-795.

Böнme, H. (1963). Mutagen stability of Proteus mirabilis against UV- and X-irradiation. Microbial Genetics Bulletin 19, 5.

BRIDGES, B. (1978). DNA polymerase and mutation. Nature, London 275, 591-592.

Bridges, B. A., Dennis, R. E. \& Munson, R. J. (1967). Differential induction and repair of ultraviolet damage leading to true reversions and external suppressor mutations of an ochre codon in Escherichia coli $\mathrm{B} / \mathrm{rWP} \mathbf{P}_{2}$. Genetics 57, 897-908.

Bridges, B. A., Mottershead, R. P. \& Green, M. H. L. (1977). Cell division in Escherichia coli $\mathrm{B}_{\mathrm{s}-12}$ is hypersensitive to deoxyribonucleic acid damage by ultraviolet light. Journal of Bacteriology 130, 724728.

Brooks, K. \& Clark, A. J. (1967). Behaviour of lambda bacteriophage in a recombination deficient strain of Escherichia coli. Journal of Virology 1, 283-293.

Brown, D. T., Brown, N. C. \& Burlingham, B. T. (1972). Morphology and physical properties of Staphylococcus bacteriophage P11-M15. Journal of Virology 9, 664-671.

Cohen, S., Sweeney, H. M. \& Basu. S. K. (1977). Mutations in prophage $\phi 11$ that impair the transducibility of their Staphylococcus aureus lysogens for methicillin resistance. Journal of Bacteriology 129, 237-245.

Defais, M., Fauquet, P.. Radman, M. \& Errera, 
M. (1971). Ultraviolet reactivation and ultraviolet mutagenesis of $\lambda$ in different genetic systems. Virology 43, 495-503.

Defais, M., Caillet-Fauquet, P., Fox, M. S. \& RADMAN, M. (1976). Induction kinetics of mutagenic DNA repair activity in $E$. coli following ultraviolet irradiation. Molecular and General Genetics 148, 125-130.

Doudney, C. O. (1976). Complexity of the ultraviolet mutation frequency response curve of Escherichia coli $\mathrm{B} / \mathrm{r}$ : SOS induction, one-lesion and two-lesion mutagenesis. Journal of Bacteriology 128, 815-826.

Garrity, F. L., Detrick, B. \& KenNedy, E. R. (1969). Deoxyribonucleic acid base composition in the taxonomy of Staphylococcus. Journal of Bacteriology 97, 557-560.

Ghosh, A., DAs, J. \& ManilofF, J. (1977). Lack of repair of ultraviolet light damage in Mycoplasma gallisepticum. Journal of Molecular Biology 116, 337-344.

Goering, R. V. \& Pattee, P. A. (1971). Mutants of Staphylococcus aureus with increased sensitivity to ultraviolet radiation. Journal of Bacteriology 106, 157-161.

Grimm, K. (1978). Comparison of spontaneous, UV-induced and nitrosoguanidine-induced mutability to drug resistance in myxobacteria. Journal of Bacteriology 135, 748-753.

Gudas, L. J. \& Pardee, A. B. (1975). Model for regulation of Escherichia coli DNA repair functions. Proceedings of the National Academy of Sciences of the United States of America 72, 2330-2334.

HARM, W. (1963). On the relationship between host cell reactivation and u.v. reactivation in u.v.inactivated phages. Zeitschrift für Vererbungslehre 94. 67-79.

HART, M. G. R. \& Ellison, J. (1970). Ultraviolet reactivation in bacteriophage lambda. Journal of General Virology 8, 197-208.

Hofemeister, J. (1977). DNA repair in Proteus mirabilis. IV. Post-irradiation DNA degradation as influenced by a function inducible in $\mathrm{rec}^{+}$cells. Molecular and General Genetics 154, 35-41.

HofEMEISTER, J. \& BÖHME, H. (1975). DNA repair in Proteus mirabilis. III. Survival, dimer excision and UV reactivation in comparison with Escherichia coli K12. Molecular and General Genetics 141, 147161 .

Howard-Flanders, P. \& Boyce, R. P. (1966). DNA repair and genetic recombination studies on mutants of Escherichia coli defective in these processes. Radiation Research Supplement 6, 156-184.

Howard-Flanders, P. \& Theriot, L. (1966). Mutants of Escherichia coli $\mathrm{K}-12$ defective in DNA repair and genetic recombination. Genetics $\mathbf{5 3}$, 1137-1150.

Hutchinson, W. G. \& Medill, M. A. (1954). The isolation of Proteus mutants and their use in recombination experiments. Bacteriological Proceedings $40-41$.

Inoue, M., Oshima, H., OKubo, T. \& Mitsuhashi, S. (1972). Isolation of the rec mutants in Staphylococcus aureus. Journal of Bacteriology 112 , 1169-1176.

Kerr, T. L. \& HART, M. G. R. (1972). Effects of the rec and exr mutations of Escherichia coli on bacteriophage lambda damaged by different agents. Mutation Research 15, 247-258.

Kimball, R. F., Boling, M. E. \& Perdue, S. W. (1977). Evidence that UV-inducible error-prone repair is absent in Haemophilus influenzae $\mathrm{Rd}$, with a discussion of the relation to error-prone repair of alkylating-agent damage. Mutation Research 44, 183-196.

LindBERG, M., SJöström, J.-E. \& Johansson, T. (1972). Transformation of chromosomal and plasmid characters in Staphylococcus aureus. Journal of Bacteriology 109, 844-847.

Novick, R. P. (1967). Properties of a cryptic highfrequency transducing phage in Staphylococcus aureus. Virology 33, 155-166.

Novick, R. P. \& BRodsky, R. (1972). Studies on plasmid replication. I. Plasmid incompatibility and establishment in Staphylococcus aureus. Journal of Molecular Biology 68, 285-302.

Pollard, E. C. \& SNipes, W. (1977). Absence of two radiation-induced repair processes in a marine pseudomonad. Photochemistry and Photobiology 26, 545-548.

RADMAN, M. (1974). Phenomenology of an inducible mutagenic DNA repair pathway in Escherichia coli: SOS repair hypothesis. In Molecular and Environmental Aspects of Mutagenesis, pp. 128-142. Edited by L. Prokash, F. Sherman, M. Miller, C. Lawrence \& H. W. Tabor. Springfield, Ill., U.S.A.: Charles C. Thomas.

Radman, M. \& Devoret, R. (1971). UV reactivation of bacteriophage $\lambda$ in excision repair deficient hosts: independence of red functions and attachment regions. Virology 43, 504-506.

Radman, M., Cordone, L., Krsmanovic-Simic, D. \& Errera, M. (1970). Complementary action of recombination and excision in the repair of ultraviolet irradiation damage to DNA. Journal of Molecular Biology 49, 203-212.

Roberts, J. W., Roberts, C. W. \& Craig, N. L. (1978). Escherichia coli recA gene product inactivates phage $\lambda$ repressor. Proceedings of the National Academy of Sciences of the United States of America 75, 4714-4718.

Rudin, L. \& LindberG, M. (1975). Thymineless bacteriophage induction in Staphylococcus aureus. I. High-frequency transduction with lysates containing a bacteriophage related to bacteriophage $\phi 11$. Journal of Virology 16, 1357-1366.

Satta, G., Gudas, L. J. \& Pardee, A. B. (1979). Degradation of Escherichia coli DNA: evidence for limitation in vivo by protein $\mathrm{X}$, the $\operatorname{rec} A$ gene product. Molecular and General Genetics 168, 69-80.

SMith, P. R. \& DunicaN, L. K. (1974). Induction and interaction of two staphylococcal phages. Proceedings of the Society for General Microbiology $2,21$.

Smith, P., Duffy, A. \& Dunican, L. K. (1975). Indirect induction of a Staphylococcus aureus prophage by P1lde a plasmid phage hybrid. Molecular and General Genetics 137, 79-83.

Sweet, D. M. \& Moseley, B. E. B. (1974). Accurate repair of ultraviolet-induced damage in Micrococcus radiodurans. Mutation Research 23, 311-318.

Sweet, D. M. \& Moseley, B. E. B. (1976). The 
resistance of Micrococcus radiodurans to killing and mutation by agents which damage DNA. Mutation Research 34, 175-186.

Villani, G., Bolteux, S. \& Radman, M. (1978). Mechanism of ultraviolet-induced mutagenesis: extent and fidelity of in vitro DNA synthesis on irradiated templates. Proceedings of the National Academy of Sciences of the United States of America 75, 3037-3041.

Weigle, J. J. (1953). Induction of mutations in a bacterial virus. Proceedings of the National Academy of Sciences of the United States of America 39, 628-636.

WITKIN, E. M. (1966). Radiation-induced mutations and their repair. Science 152, 1345-1353.

WitKIN, E. M. (1974). Thermal enhancement of ultraviolet mutability in a tif-1 uvrA derivative of Escherichia coli $\mathrm{B} / \mathrm{r}$ : evidence that ultraviolet mutagenesis depends upon an inducible function. Proceedings of the National Academy of Sciences of the United States of America 71, 1930-1934.

WITKIN, E. M. (1976). Ultraviolet mutagenesis and inducible DNA repair in Escherichia coli. Bacteriological Reviews 40, 869-907.

Wyman, L., Goering, R. V. \& Novick, R. P. (1974). Genetic control of chromosomal and plasmid recombination in Staphylococcus aureus. Genetics 76, 681-702.

YASBIN, R. E. $(1977 a)$. DNA repair in Bacillus subtilis. 1. The presence of an inducible system. Molecular and General Genetics 153, 211-218.

YASBIN, R. E. $(1977 b)$. DNA repair in Bacillus subtilis. II...Activation of the inducible system in competent bacteria. Molecular and General Genetics 153, 219-225. 